\title{
Theoretical and Case Studies of Interval Nonprobabilistic Reliability for Tailing Dam Stability
}

\author{
Longjun Dong, Daoyuan Sun, and Xibing Li \\ School of Resources and Safety Engineering, Central South University, Changsha 410083, China \\ Correspondence should be addressed to Longjun Dong; lj.dong@csu.edu.cn
}

Received 31 May 2017; Revised 24 July 2017; Accepted 31 July 2017; Published 28 September 2017

Academic Editor: Qinghui Jiang

Copyright (C) 2017 Longjun Dong et al. This is an open access article distributed under the Creative Commons Attribution License, which permits unrestricted use, distribution, and reproduction in any medium, provided the original work is properly cited.

\begin{abstract}
The stability of the operation of a tailing dam is affected by reservoir water level, phreatic line, and mechanical parameters of tailings. The values of these factors are not a definite value in different situations. Meanwhile, the existence of the phreatic line makes it a more complex issue to analyze the stability of the tailing dam. Additionally, it is very hard to give a definite limit to the state of tailing dam from security to failure. To consider the uncertainty when calculating the stability of the tailing dams, interval values are used to indicate the physical and mechanical parameters of tailings. An interval nonprobabilistic reliability model of the tailing dam, which can be used when the data is scarce, is developed to evaluate the stability of the tailing dam. The interval nonprobabilistic reliability analysis model of tailing dam is established in two cases, including with and without considering phreatic line conditions. The proposed model was applied to analyze the stability of two tailing dams in China and the calculation results of the interval nonprobabilistic reliability are found to be in agreement with actual situations. Thus, the interval nonprobabilistic reliability is a beneficial complement to the traditional analysis method of random reliability.
\end{abstract}

\section{Introduction}

Tailing dam failure is a type of major hazard source in China. The damage of the tailing dam failure is much worse than that of an ordinary dam, and meanwhile, it causes serious environment pollution. The stability of a tailing dam is the main measure indicator of the safety of tailing pond. The failure of a tailing dam not only will seriously affect the normal production of the mine, but also will cause serious damage to the local industrial and agricultural production and property of the people living downstream.

The study of tailing dams is similar to that of slopes. Through the introduction and intersection of some new disciplines and theories, some new methods of slope stability analysis, such as reliability analysis based on the probability theory and mathematical statistics $[1,2]$, the comprehensive evaluation method based on the fuzzy/statistical mathematics [3-6], the gray system evaluation method based on the gray system theory [7-11], and the neural network evaluation method based on the neural network theory [12-16], are gradually formed. These evaluation methods have achieved good application in slope stability analysis and evaluation and promoted the development of slope stability research.

In the evaluation of the stability of tailing dams, the currently used evaluation methods are mainly from the evaluation methods of traditional slope stability analysis. There are many ways to determine the slope stability level, but the evaluation results of traditional methods using single index or few indexes, with great limitations and one-sidedness, are sometimes contradictory and difficult to choose. The comprehensive evaluation method using multi-index developed in recent years has been proved to be an effective way to improve the accuracy of evaluation. The rock mass of tailing dam is a complex geological media, with complex and changing mechanical parameters, distributions of structural planes, engineering properties, and strong uncertainty. The existence of these uncertainties brings great difficulties to the stability analysis of tailing dams. Although a lot of methods have been developed, the difficulty of stability evaluation of the tailing dam lies in the uncertainty of many factors, how to take this uncertain information into account when analyzing stability of the tailing dams is an important issue worthy of 
studying. The unascertained theory provides a better way in this respect. Therefore, it is necessary to introduce reliability analysis in stability analysis of tailing dams.

The phreatic line is one of the most important factors affecting the stability of the tailings dam [17]. The safety factor of stability can increase 0.05 or more while the phreatic line drops $1 \mathrm{~m}$. Therefore, the determination of the phreatic line is one of the most important contents in the study of the stability of tailing dams and also the first problem to be solved.

Therefore, it is of great significance to study the dam failure mechanism and investigate the reliable monitoring technology to predict the potential dam instability according to the monitoring results. In recent years, many experts and scholars did a lot of exploration and research in the above two aspects.

Blight [18] studied the failures of five annular tailing dams in South Africa and concluded that the transport distance of the tailing flow is related to the wet state of the surface, the transport distance of tailing flow is longer in the wet surface than that in the dry surface. In addition, Moxon [19] investigated the tailing dam accident in the Los Frailes mine in southern Spain and proposed a method to prevent the failure of tailing dam. Rico et al. [20] collected the effective information of the historical failure of tailing dam and analyzed and summarized the relationship between the geometrical parameters of the tailing dam and the characteristics of the tailing flow produced by the tailing dam failure. This study has an important practical significance to the analysis of the relationship between the tailing dam failure and the parameters of the tailing dam and also to the evaluation of tailing dam failure.

In the monitoring and early warning of tailing dam failure, based on the support vector regression and the monitoring data of the tailing dam, Li et al. [21] presented a new prediction method for phreatic line. Wang [22] applied the gray theory and support vector machine theory to the prediction of tailing dam displacement and phreatic line based on the monitoring results of tailing dam displacement and the phreatic line, which provided a new method for the stability analysis and reliability prediction of tailing dam. Jiang et al. $[23,24]$ proposed a general approximate method for the groundwater response problem caused by water level variation, and they also investigated the approximate analytical solution to the Boussinesq equation with a sloping water-land boundary, which can be used to determine the phreatic line under different water levels in tailing dam under the conditions without the measured data of observation holes.

The currently used safety factor method [25] and random reliability method [26] are not effective in solving the problem of real-time stability of tailing dam. The reason is that the safety factor method cannot consider the randomness of parameters; although the random reliability method takes the randomness of the parameters into consideration, but due to the huge workload and high cost of the repeated trial in the actual project, the coefficient of variation is often assumed or obtained by simple calculation and did not take into account the time correlation.
The interval nonprobabilistic reliability analysis methods for structures [27-33] based on interval theory provide a useful approach to evaluate these uncertainties. Interval values can better reflect the uncertainty of a parameter value when the number of samples is scarce, thus reducing the demand for data information.

Based on the complexity, the randomness, and the parameters uncertainty of the tailing dam, aiming at effectively evaluating the reliability of the tailing dam, the interval nonprobabilistic reliability analysis model of tailing dam is established in two cases, including with and without considering phreatic line conditions.

\section{Limit State Equation of the Tailing Dam Failure}

2.1. With the Consideration of the Effect of Phreatic Line on the Tailing Dam. During the normal operation of a tailing dam, the phreatic line is usually between the most dangerous sliding face and the slope. The evaluation of the tailing dam stability must take into account the influence of the phreatic line. The calculation equations of resistance $R$ and load effect $S$ of the most common case are analyzed next.

To obtain the most accurate calculation results, the effect of hydraulic force was considered. The direction of hydraulic force and vertical direction is not consistent; it cannot simply apply the treatment of tailing gravity. In fact, the essential of using arc method to analyze the stability of the slope is to consider the relative size of the sliding moment and antisliding moment; the reason why the situation without considering the phreatic line can use the sliding force and resistance is a special case where the sliding force and resistance have an equal arm to the center. Therefore, we replace the sliding force and resistance by the moments of sliding force and resistance. As the location direction of the hydraulic force is easy to determine, the use of moment also simplified the analysis and calculation.

As shown in Figure 1, the slope equation $g(x)$ indicates the equation of the tailing dam surface in the vertical projection, which is determined by fitting the coordinates of points in the surface of the tailing dam. The equation of the circular sliding face $f(x)$ is calculated by the Swedish Circle Method. The equation of the phreatic line $\omega(x)$ is fitted by the measured data of water level in phreatic line observation holes. The area of the part $f g B f$ modeled by the phreatic line, the slope, and the sliding face is $W$. The hydraulic force acting on the part $f g B f$ is $D$, whose action point is the centroid of the area. The direction of action can be assumed to be parallel with the direction of $f g$ (as indicated by the arrow in the figure). The arm of the hydraulic force to the center of sliding face is $L_{1} . h_{1 i}$ and $h_{2 i}$ indicate the length of the vertical tailings above and below the phreatic line, respectively.

The hydraulic force can be expressed as

$$
D=G_{D} I W=\gamma_{w} I W,
$$

where $G_{D}$ is the hydraulic force acting on per unit volume, $\gamma_{w}$ is the bulk weight of water, and $I$ is the mean value of the water 


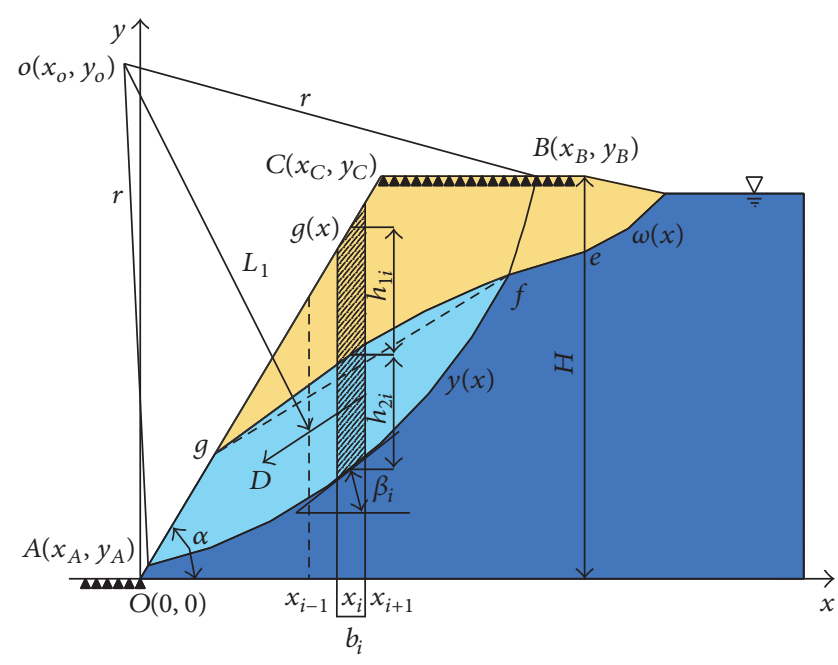

FIGURE 1: Slope section of the arc of destruction with considering the impact of phreatic line.

table gradient in the sphere of $f g B f$, which can be assumed equal to the gradient of line $f g$.

As to calculating the weight of the $i$ section of the tailings, for the part below the phreatic line, the buoyancy of the water should be taken into account when the resistance is calculated, and the saturated bulk density should be used if the sliding force is calculated.

Therefore, the equations for calculating the resistance $M R$ and sliding force $M S$ of the tailing dam with the consideration of the phreatic line can be expressed as

$$
\begin{aligned}
M R & =\sum_{i=1}^{n}\left\{c l_{i}+\left[W_{i} \cos \beta_{i}-\mu_{i} l_{i}\right] f\right\} r=\sum_{i=1}^{n}\left\{\frac{c b_{i}}{\cos \beta_{i}}\right. \\
& \left.+\left[\left(\gamma h_{1 i}+\gamma_{\text {sat }} h_{2 i}\right) \cos \beta_{i}-\frac{\gamma_{w} h_{2 i}}{\cos \beta_{i}}\right] b_{i} f\right\} r, \\
M S & =\sum_{i=1}^{n}\left(W_{i} \sin \beta_{i}\right) r+L_{1} D \\
& =\sum_{i=1}^{n}\left(\left[\gamma h_{1 i}+\gamma_{\text {sat }} h_{2 i}\right] b_{i} \sin \beta_{i}\right) r+L_{1} D .
\end{aligned}
$$

If the tailings are divided into infinite vertical sections, (2) can be written as

$$
\begin{aligned}
M R & =r \int_{x_{B}}^{x_{A}}\left\{\frac{c}{\cos \beta}\right. \\
& +\left\{\left[\gamma[g(x)-\omega(x)]+\gamma_{\text {sat }}[\omega(x)-y(x)]\right] \cos \beta\right. \\
& \left.\left.-\frac{\gamma_{w}[\omega(x)-y(x)]}{\cos \beta}\right\} f\right\} d x,
\end{aligned}
$$

$$
\begin{aligned}
M S & =\int_{x_{B}}^{x_{A}}\left(x-x_{0}\right)\left[\gamma[g(x)-\omega(x)]+\gamma_{\text {sat }}[\omega(x)\right. \\
& -y(x)]] d x+L_{1} D .
\end{aligned}
$$

To simplify the two equations, we note the resistance $M R$ and sliding force $M S$ as

$$
\begin{aligned}
& M R=k_{1} f+k_{2} c, \\
& M S=k_{3},
\end{aligned}
$$

where

$$
\begin{aligned}
k_{1}=r \int_{x_{B}}^{x_{A}}\left\{\left[\gamma[g(x)-\omega(x)]+\gamma_{\text {sat }}[\omega(x)-y(x)]\right]\right. \\
\left.. \frac{\sqrt{r^{2}-\left(x-x_{0}\right)^{2}}}{r}-\frac{r \gamma_{w}[\omega(x)-y(x)]}{\sqrt{r^{2}-\left(x-x_{0}\right)^{2}}}\right\} d x, \\
k_{2}=2 r^{2} \arcsin \frac{\sqrt{\left(x_{B}-x_{A}\right)^{2}+\left(y_{B}-y_{A}\right)^{2}}}{2 r}, \\
k_{3}=\int_{x_{B}}^{x_{A}}\left(x-x_{0}\right)\left[\gamma[g(x)-\omega(x)]+\gamma_{\text {sat }}[\omega(x)\right. \\
-y(x)]] d x+L_{1} D .
\end{aligned}
$$

Therefore, the limit state equation of the tailing dam failure can be written as

$$
Z=M R-M S=k_{1} f+k_{2} c-k_{3} .
$$

This equation can divide the steady statue of tailing dam into three conditions; namely, the tailing dam is reliable if $Z>$ 0 , the tailing dam is in the limit state if $Z=0$, and the tailing dam is unreliable if $Z<0$.

2.2. Without the Consideration of the Effect of Phreatic Line on the Tailing Dam. The tailing dam model without phreatic line is established in the same manner with the model of Section 2.1. As shown in Figure 2, the slope equation is $g(x)$; the equation of the circular sliding face is $f(x)$. The equations for calculating the resistance $M R$ and sliding force $M S$ of the tailing dam without the consideration of the phreatic line can be expressed as

$$
\begin{aligned}
& M R=\sum_{i=1}^{n}\left(f \cdot W_{i} \cdot \cos \beta_{i}+c \cdot l_{i}\right), \\
& M S=\sum_{i=1}^{n} W_{i} \cdot \sin \beta_{i} .
\end{aligned}
$$




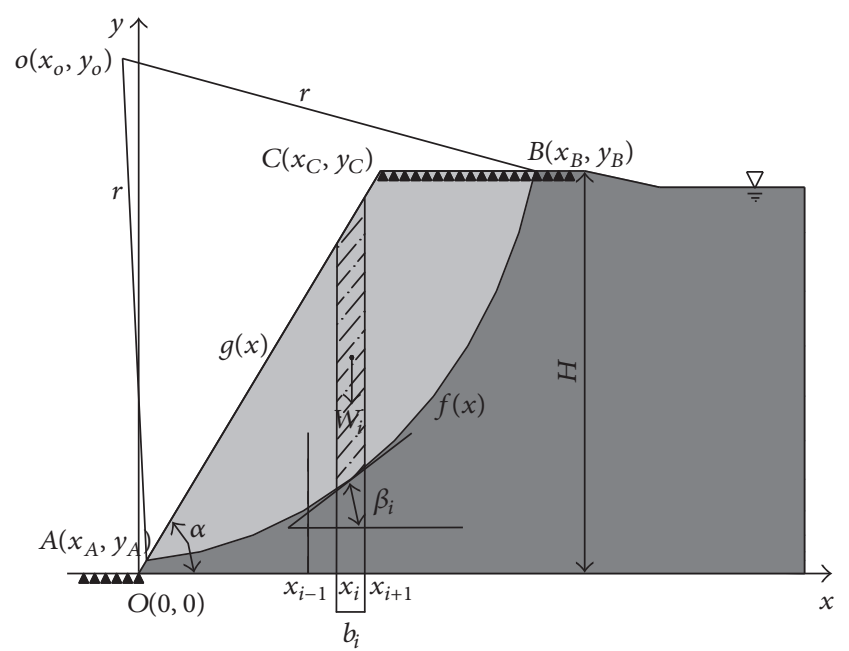

FIGURE 2: Slope section of the arc of destruction without considering the impact of phreatic line.

If the tailings are divided into infinite vertical sections, (7) can be written as

$$
\begin{aligned}
M R= & \int_{x_{A}}^{x_{B}} \frac{\gamma \cdot f \cdot[g(x)-f(x)]}{\sqrt{1+f^{\prime 2}(x)}} d x \\
& +\int_{x_{A}}^{x_{B}} c \cdot \sqrt{1+f^{\prime 2}(x)} d x, \\
M S= & \int_{x_{A}}^{x_{B}} \frac{\gamma \cdot[g(x)-f(x)] \cdot f^{\prime}(x)}{\sqrt{1+f^{\prime 2}(x)}} d x .
\end{aligned}
$$

To simplify the two equations, we note the resistance $M R$ and sliding force $M S$ as

$$
\begin{aligned}
& M R=m_{1} c+m_{2} f, \\
& M S=m_{3},
\end{aligned}
$$

where

$$
\begin{aligned}
& m_{1}=\int_{x_{A}}^{x_{B}} \sqrt{1+f^{\prime 2}(x)} d x, \\
& m_{2}=\int_{x_{A}}^{x_{B}} \frac{\gamma[g(x)-f(x)]}{\sqrt{1+f^{\prime 2}(x)}} d x, \\
& m_{3}=\int_{x_{A}}^{x_{B}} \frac{\gamma[g(x)-f(x)] \cdot f^{\prime}(x)}{\sqrt{1+f^{\prime 2}(x)}} d x .
\end{aligned}
$$

Therefore, the limit state equation of the tailing dam failure can be written as

$$
Z=M R-M S=m_{1} c+m_{2} f-m_{3} .
$$

This equation can divide the steady statue of tailing dam into three conditions; namely, the tailing dam is reliable if $Z>$ 0 , the tailing dam is in the limit state if $Z=0$, and the tailing dam is unreliable if $Z<0$.

\section{Interval Nonprobabilistic Reliability Method for Tailing Dam Failure}

Uncertainty theory has developed rapidly and has been widely applied in recent years. Ben-Haim et al. [30] proposed the uncertainty convex model to address the deficiencies of the probabilistic model. Subsequently, Guo [32] established a theoretical interval nonprobabilistic reliability model for evaluating the reliability of structures. In this paper, the theory of interval nonprobabilistic reliability is used to analyze the reliability of tailing dams. The interval nonprobabilistic reliability $\eta$ of a tailing dam is defined as the minimum distance of the normalized failure surface from origin of $\mathbb{C}^{n}$, and the distance is measured in $l_{\infty}$ norms. $\eta=1$ means that the most probable failure point is located on the boundary of failure domain, and the reliability of rock mass structure has reached a critical state. For the case of $0 \leq \eta<1$, some combinations of uncertain parameters may be out of the reliable domain. The tailing dam cannot satisfy the reliability requirement. When $\eta>1$, all possible points of the tailing dam lie into the reliable domain, which indicate that the tailing dam is safe and reliable. To guarantee the safety tailing dam and obtain adequate safety margin, the interval nonprobabilistic reliability $\eta$ can choose to be larger than 1 .

The interval values of the shear strength parameters of a tailing dam are $\left[c^{l}, c^{u}\right]$ and $\left[\varphi^{l}, \varphi^{u}\right]$. Suppose that the interval nonprobabilistic reliability of the tailing dam is $\eta$. When $\eta>$ 1 , the tailing dam is reliable; otherwise, it is unreliable. A larger value of $\eta$ indicates a higher level of reliability. An interval nonprobabilistic reliability solution method should be further established using the method described above to analyze the reliability comprehensively. For the convenience of analysis, according to the interval value standardization method, interval performance equations (6) and (11) are transformed into standard form; namely,

$$
\begin{aligned}
Z & =M R-M S \\
& =k_{1} \times\left(f^{c}+f^{r} \delta_{f}\right)+k_{2} \times\left(c^{c}+c^{r} \delta_{c}\right)-k_{3}, \\
Z & =M R-M S \\
& =m_{1} \times\left(c^{c}+c^{r} \delta_{c}\right)+m_{2} \times\left(f^{c}+f^{r} \delta_{f}\right)-m_{3},
\end{aligned}
$$

where $\left(f^{c}+f^{r} \delta_{f}\right)$ and $\left(c^{c}+c^{r} \delta_{c}\right)$ are the interval shear strengths of the tailing dam, $c^{c}=\left(c^{l}+c^{u}\right) / 2, c^{r}=\left(c^{u}-c^{l}\right) / 2$, $\left[c^{l}, c^{u}\right]=c^{c} \pm c^{r} \delta_{c}, f^{c}=\left(f^{l}+f^{u}\right) / 2, f^{r}=\left(f^{u}-f^{l}\right) / 2$, $\left[f^{l}, f^{u}\right]=f^{c} \pm f^{r} \delta_{c}$, and $\delta_{f}, \delta_{c} \in[-1,1]$.

According to the nonprobabilistic reliability theory, the equations of the interval nonprobabilistic reliability $\eta$ for the standardized interval performance function (12a) and (12b) can be solved as

$$
\eta=\min \left\{\|\delta\|_{\infty}\right\}
$$

and meet the condition

$$
Z=0 \text {. }
$$

To establish a method for solving the interval nonprobabilistic reliability $\eta$, based on previous studies, Jiang et al. [31] proposed a one-dimensional optimization algorithm that 
can effectively avoid interval extension when calculating the complex performance function. The paper will apply this method to solve the interval nonprobabilistic reliability. The specific analysis process is described below.

(1) When considering the failure of a tailing dam, list 2 super radiation lines/ultra-rays that pass through the origin $O_{\delta_{1}}^{\infty}=\left\{\boldsymbol{\delta}_{1}: \delta_{1 k}=0, k=1,2\right\}$ of the $\delta_{1}$ expansion space $C_{\delta_{1}}^{\infty}=$ $\left\{\boldsymbol{\delta}_{1}: \delta_{1 k} \in(-\infty,+\infty), k=1,2\right\}$ and the vertex $P_{\delta_{1}}^{j}=$ $\left\{\boldsymbol{\delta}_{1}:\left|\delta_{1 k}\right|=1, k=1,2\right\}(j=1,2,3,4)$ of the symmetric convex domain $C_{\delta_{1}}^{\infty}=\left\{\delta_{1}:\left|\delta_{1 k}\right| \leq 1, k=1,2\right\}$ formed by $\delta_{1}$. These super radiation lines/ultra-rays are marked as $\delta_{11}= \pm \delta_{12}$, meeting the condition $\delta_{1} \in C_{\delta_{1}} \subset C_{\delta_{1}}^{\infty}$.

(2) Add $\delta_{11}= \pm \delta_{12}$ and $m=1$ to (14) to solve the interval nonprobabilistic reliability; 2 high-order nonlinear equations can be obtained, and the interval nonprobabilistic reliability set $\left\{\eta_{11}, \eta_{12}\right\}$ can be solved using a numerical method.

(3) The complex solutions are abandoned, and the absolute value of the real solution is selected. The minimum will be the interval nonprobabilistic reliability $\eta$ of the tailing dam.

\section{Case Studies}

4.1. A Case Study of the Tailing Dam of Hengyang. Located in the Qidong County, Hengyang, the tailing dam lies downstream of the mine. The tailing pond is like an ellipse, with the length of $500 \mathrm{~m}$ and the width of $200 \mathrm{~m}$. The tailing dam is surrounded by mountains, with big topographic inequality; the altitude of the mountain is $390 \mathrm{~m}$ in the north side, $385 \mathrm{~m}$ in the west side, and $378 \mathrm{~m}$ in the east side. The lowest altitude of the tailing pond is $285 \mathrm{~m}$. The degree of seismic fortification intensity is 6 , and the designed earthquake acceleration is $0.05 \mathrm{~g}$. The initial dam is rock fill dam, with a bottom elevation of $284 \mathrm{~m}$, and a top elevation of $316 \mathrm{~m}$. The granule gradations are as follows: hunch rock (above $60 \mathrm{~kg}$ ) 75\%, fit rock (30-60 kg) 15\%, and small rock (3-30 kg) 5\%. The cross section map of tailing dam of Hengyang is shown in Figure 3. The tailings consist of tailing medium sand, tailing silty sand, tailing fine sand, tailing mild sand, tailing mild clay, and tailing mud.

According to engineering investigation of the tailings dam, the physical and mechanical parameters of the tailing dam are shown in Table 1 . The equation of sliding face crosses the layers of all the six earth species; therefore, the interval values of the shear strength parameters are determined by the minimum and maximum values of internal friction angle and cohesion of the six tailing species. The interval values of the shear strength parameters are shown in Table 2.

The equation of sliding face can be expressed as

$$
f(x)=174-\left(179.7^{2}-(x-38.8)^{2}\right)^{0.5} .
$$

The equation of the slope can be expressed as

$$
g(x)= \begin{cases}0.33 x & x \leq 194 \\ 60 & x>194\end{cases}
$$

The equation of the phreatic line can be expressed as

$\omega(x)$

$$
= \begin{cases}0.31 x & x \leq 47.731 \\ 0.11 x+6.88 & x \leq 148.72 \\ 174+\left(179.7 x^{2}-(x-38.8)^{2}\right)^{0.5} & x>148.72 .\end{cases}
$$

By substituting the known parameters in (5) and (15) to (17), the values of $k_{1}, k_{2}$, and $k_{3}$ can be obtained and are listed below.

$$
\begin{aligned}
& k_{1}=8.37773 \times 10^{6}, \\
& k_{2}=25552, \\
& k_{3}=2.83188 \times 10^{6} .
\end{aligned}
$$

Therefore, the limit state equation of the tailing dam can be expressed as

$$
\begin{aligned}
Z & =M R-M S \\
& =8.37773 \times 10^{6} \times f+25552 \times c-2.83188 \times 10^{6} .
\end{aligned}
$$

The limit state equation can be transformed into standard form by using the standardize method of interval values; namely,

$$
\begin{aligned}
Z= & M R-M S \\
= & 8.37773 \times 10^{6} \times\left(f^{c}+f^{r} \delta_{f}\right)+25552 \\
& \times\left(c^{c}+c^{r} \delta_{c}\right)-2.83188 \times 10^{6} .
\end{aligned}
$$

By substituting the mean value and deviation of $c$ and $f$ into (20) and using the method introduced in Section 3, the interval nonprobabilistic reliability index can be solved.

$$
\begin{aligned}
Z= & M R-M S \\
= & 8.37773 \times 10^{6} \times\left(0.46805+0.05035 \delta_{f}\right)+25552 \\
& \times\left(0.0265+0.0035 \delta_{c}\right)-2.83188 \times 10^{6}=0 .
\end{aligned}
$$

Solve the equation above and the interval nonprobabilistic reliability index $\beta$ was obtained.

$$
\beta=1.63783 \text {. }
$$

The calculated random and fuzzy random reliability are 0.9627 and 0.8534 , respectively, which means that the two kinds of reliability indexes are 1.78 and 1.05. The interval nonprobabilistic reliability index is 1.63783 . The results suggest that the tailing dam is in a totally reliable status. Actually, the appearance of the dam is in a good condition, without the occurrence of deep or shallow sliding signs, and also no horizontal and vertical cracks are found. The actual situation is consistent with the calculation results, which means that the interval nonprobabilistic reliability model is a reasonable one and can be used to analyze the stability of tailing dam. 


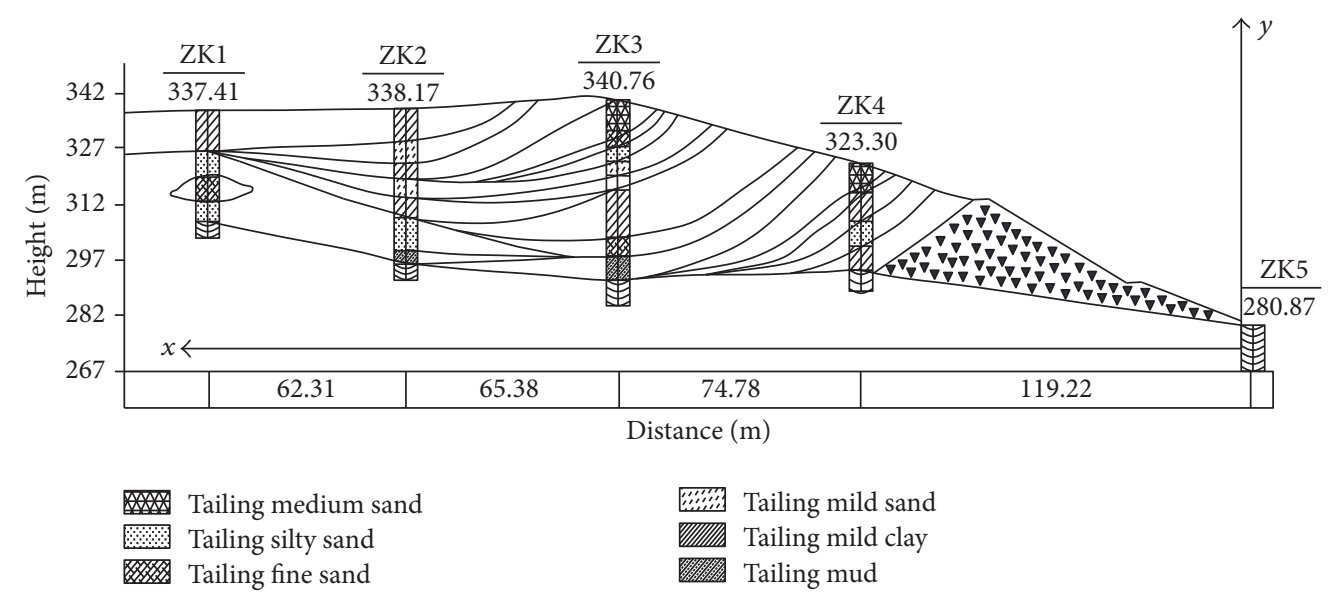

FIGURE 3: Cross section map of tailing dam of Hengyang. The ZK1 to ZK5 are the sampling holes. The legends show the constituents of the tailings. The tailings consist of tailing medium sand, tailing silty sand, tailing fine sand, tailing mild sand, tailing mild clay, and tailing mud. The distances between sampling holes are noted below the graph.

TABLE 1: The physical and mechanical parameters of the tailing dam.

\begin{tabular}{|c|c|c|c|c|c|c|c|c|}
\hline \multirow{3}{*}{ Earth species } & \multirow{3}{*}{$\begin{array}{c}\text { Natural weightiness } \\
\text { degree } / \mathrm{kN} / \mathrm{m}^{3}\end{array}$} & \multicolumn{6}{|c|}{ Shear strength } & \multirow{3}{*}{$\begin{array}{c}\text { Permeability } \\
\text { coefficient } / \mathrm{cm} \cdot \mathrm{s}^{-1}\end{array}$} \\
\hline & & \multicolumn{3}{|c|}{ Internal friction angle $/^{\circ}$} & \multicolumn{3}{|c|}{ Cohesion $/ \mathrm{kPa}$} & \\
\hline & & $\varphi_{\min }$ & $\varphi_{\max }$ & $\varphi_{\text {mean }}$ & $c_{\min }$ & $c_{\max }$ & $c_{\text {mean }}$ & \\
\hline Tailing medium sand & 15.02 & 24 & 29.3 & 26.65 & 27 & 43 & 35 & $1.49 \times 10^{-3}$ \\
\hline Tailing silty sand & 19.17 & 25.5 & 27.3 & 26.4 & 27 & 67.2 & 47.1 & $4.31 \times 10^{-4}$ \\
\hline Tailing fine sand & 19.86 & 26 & 30 & 28 & 18.2 & 47.1 & 32.65 & $1.45 \times 10^{-4}$ \\
\hline Tailing mild sand & 19.9 & 26 & 29 & 27.5 & 22.5 & 25.7 & 24.1 & $7.82 \times 10^{-4}$ \\
\hline Tailing mild clay & 19.9 & 21.6 & 28.8 & 25.2 & 28 & 35.2 & 31.6 & $8.12 \times 10^{-4}$ \\
\hline Tailing mud & 18.5 & & & 27.4 & & & 23 & $2.67 \times 10^{-6}$ \\
\hline
\end{tabular}

TABLE 2: The interval values of the shear strength parameters.

\begin{tabular}{|c|c|c|c|}
\hline Shear strength parameters & Interval values of the parameters & Mean value & Deviation \\
\hline Cohesive strength $c / \mathrm{MPa}$ & {$[0.0182,0.0672]$} & 0.0427 & 0.0245 \\
\hline Internal friction angle $\varphi /^{\circ}$ & {$[21.6,30]$} & & \\
\hline Friction coefficient $\tan \varphi$ & {$[0.3959,0.5774]$} & 0.48665 & 0.09075 \\
\hline
\end{tabular}

4.2. A Case Study for the Tailing Dam of Panzhihua. The Panzhihua area is located in the southwest earthquake activity area of China, where the basic seismic intensity is 7 degrees. The tailings pond is built through the upstream dam-building method, where the accumulation slope is $1: 6$, the final height of dam is $210 \mathrm{~m}$, the final accumulation elevation is $1300 \mathrm{~m}$, the storage capacity is 0.184 billion cubic meters, and the effective storage capacity is 0.16 billion cubic meters. The requirements for storing up all the tailings of Lanjian iron mine and Zhujiabao iron mine can be satisfied.

There are six characteristics of the tailings fill dam, which are the thick front, the fine tail, the thick upper layer, the fine lower layer, the thick western section, and the fine eastern section. Specially, the particle size becomes finer gradually from the slope of tailings fill dam to the inside tailings dam. The tailings are fine when close to the slope of $250 \mathrm{~m}$ range. Then, the tailings become silty as the area moves to the ditch.
The tailings in the bottom are mainly silty clay. As for the slope and the crest of the tailings fill dam considered in the vertical direction, the tailings of upper layer of 25-30 $\mathrm{m}$ range are fine, the lower layer is the powder clay mostly, and the bottom layer is the clay tailings basically. In the early stage, the particle size of tailings is fine for the areas below the elevation of dam crest. The main reason is that the production and ore-drawing are operated after the build of tailings dam for a period of time; the rainfall water in the front of the tailings dam has an impact on the particle size of tailings. In addition, the ore-drawing in the west side of the tailings dam is operated through single tube when building the third subdam, which caused the particle size of tailings to be fine in front of the auxiliary dam. The cross section map of tailings dam of Panzhihua is shown in Figure 4, where I, II, III, IV, and $\mathrm{V}$ indicate the region of rock fill, fine tailings, powder tailings, clay tailings, and powder clay, respectively. 
TABLE 3: The physical and mechanical parameters of the tailing dam.

\begin{tabular}{|c|c|c|c|c|c|c|c|c|c|}
\hline \multirow{3}{*}{ Earth species } & \multirow{3}{*}{$\begin{array}{c}\text { Natural weightiness } \\
\text { degree } / \mathrm{kN} / \mathrm{m}^{3}\end{array}$} & \multicolumn{6}{|c|}{ Shear strength } & \multirow{2}{*}{\multicolumn{2}{|c|}{$\begin{array}{c}\text { Permeability } \\
\text { coefficient } / \mathrm{cm} \cdot \mathrm{s}^{-1}\end{array}$}} \\
\hline & & \multicolumn{3}{|c|}{ Internal friction angel $/^{\circ}$} & \multicolumn{3}{|c|}{ Cohesion $/ \mathrm{kPa}$} & & \\
\hline & & $\varphi_{\min }$ & $\varphi_{\max }$ & $\varphi_{\text {mean }}$ & $c_{\min }$ & $c_{\max }$ & $c_{\text {mean }}$ & Vertical & Horizontal \\
\hline Tailing fine sand & 20.2 & 31.9 & 41.4 & 36.9 & 0.7 & 34.6 & 12.3 & $1.6 \times 10^{-3}$ & $2.0 \times 10^{-3}$ \\
\hline Tailing silty sand & 20.1 & 30.2 & 39.6 & 34.2 & 11.2 & 32.7 & 19.2 & $6.8 \times 10^{-4}$ & $1.5 \times 10^{-3}$ \\
\hline Clay tailings & 22.0 & 26.1 & 35 & 31.4 & 12.9 & 36.6 & 22.9 & $6.0 \times 10^{-5}$ & $7.5 \times 10^{-4}$ \\
\hline Powder clay & 20.5 & 1.1 & 18.9 & 6.6 & 17.9 & 24.7 & 20.3 & $2.2 \times 10^{-6}$ & $2.8 \times 10^{-6}$ \\
\hline
\end{tabular}

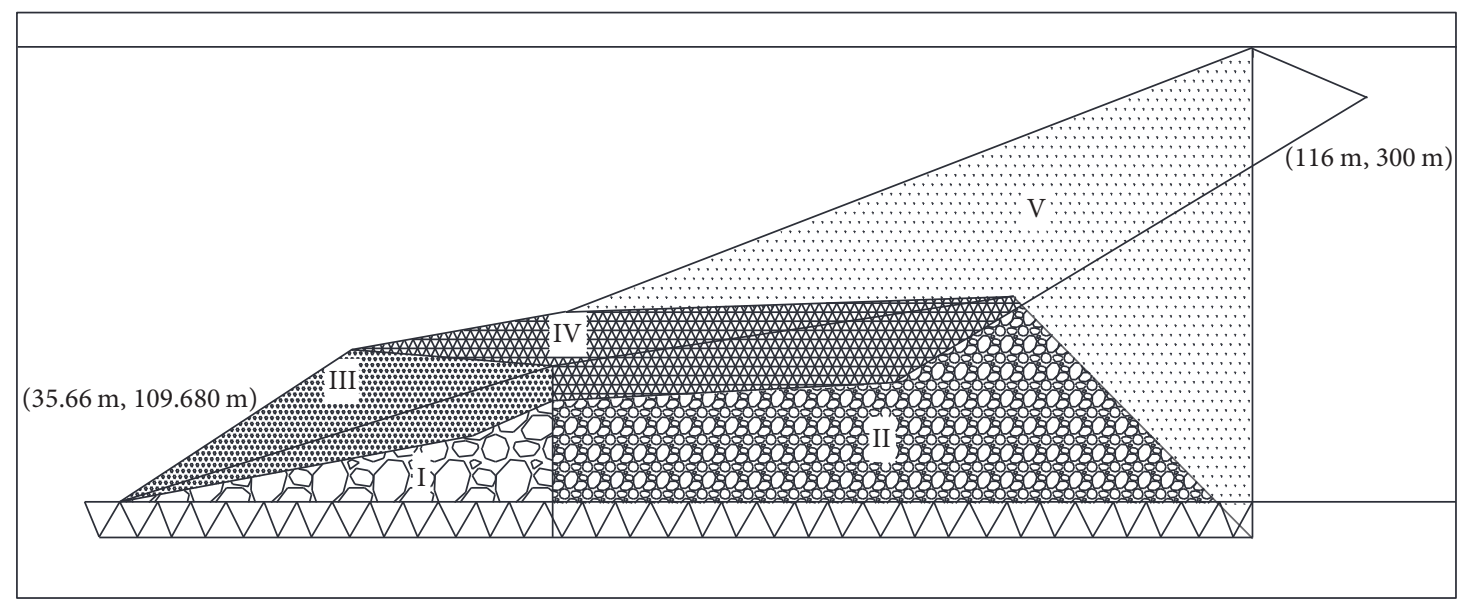

FIgURE 4: Cross section map of tailing dam of Panzhihua: I, II, III, IV, and V indicate the regions of rock fill, tailing fine sand, tailing silty sand, clay tailings, and powder clay, respectively.

According to engineering investigation of the tailings dam, the physical and mechanical parameters of the tailing dam are shown in Table 3. The equation of sliding face crosses the regions of III, I,V and V; therefore, the interval values of the shear strength parameters are determined by taking the minimum and maximum values of internal friction angle and cohesion of tailing silty sand, clay tailings, and powder clay. The interval values of the shear strength parameters are shown in Table 4.

The equations of sliding face can be expressed as

$$
f(x)=109.68-\left(100.56^{2}-(x-35.66)^{2}\right)^{0.5} .
$$

The equation of the slope can be expressed as

$$
g(x)= \begin{cases}0.45 x & x \leq 100 \\ 0.15 x+30 & 100<x \leq 200 \\ 0.18 x+40 & 200<x \leq 500 \\ 130 & x>500 .\end{cases}
$$

The equation of the phreatic line can be expressed as

$$
\omega(x)= \begin{cases}0.17 x & x \leq 165 \\ 0.29 x-28.58 & 165<x \leq 215 \\ 0.09 x+15.34 & 215<x \leq 375 \\ 0.4 x-102.2 & x>375 .\end{cases}
$$

The phreatic line is not considered while calculating the interval nonprobabilistic reliability index because the equations of sliding face and phreatic line have no intersecting point. By substituting the known parameters in (10) and (23) to (25), the values of $m_{1}, m_{2}$, and $m_{3}$ can be obtained and are listed below.

$$
\begin{aligned}
& m_{1}=103.936, \\
& m_{2}=1.99601 \times 10^{6}, \\
& m_{3}=789.469 .
\end{aligned}
$$

Therefore, the limit state equation of the tailing dam can be expressed as

$$
\begin{aligned}
Z & =M R-M S \\
& =103.936 \times c+1.99601 \times 10^{6} \times f-789.469 .
\end{aligned}
$$

The limit state equation can be transformed into standard form by using the standardize method of interval values; namely,

$$
\begin{aligned}
Z= & M R-M S \\
= & 103.936 \times\left(c^{c}+c^{r} \delta_{c}\right)+1.99601 \times 10^{6} \\
& \times\left(f^{c}+f^{r} \delta_{f}\right)-789.469 .
\end{aligned}
$$


TABLE 4: The interval values of the shear strength parameters.

\begin{tabular}{|c|c|c|c|}
\hline Shear strength parameters & Interval values of the parameters & Mean value & Deviation \\
\hline Cohesive strength $c / \mathrm{MPa}$ & {$[0.0112,0.0366]$} & 0.0239 & 0.0127 \\
\hline Internal friction angle $\varphi /^{\circ}$ & {$[1.1,39.6]$} & & \\
\hline Friction coefficient $\tan \varphi$ & {$[0.0192,0.8273]$} & 0.42325 & 0.40405 \\
\hline
\end{tabular}

TABLE 5: The advantages and disadvantages of the safety factor, the random reliability, and the nonprobabilistic reliability.

\begin{tabular}{|c|c|c|c|}
\hline Methods & The considered parameters & Advantages & Disadvantages \\
\hline Safety factor & $\begin{array}{l}\text { The mean values of the } \\
\text { mechanical parameters. }\end{array}$ & Easy to operate. & $\begin{array}{l}\text { The uncertainty of the } \\
\text { parameters is not considered. }\end{array}$ \\
\hline Random reliability & $\begin{array}{l}\text { The mean values and the } \\
\text { probability density functions of } \\
\text { the mechanical parameters. }\end{array}$ & $\begin{array}{l}\text { The uncertainty of the } \\
\text { parameters are considered; the } \\
\text { reliability index and the } \\
\text { probability of failure can be } \\
\text { obtained. }\end{array}$ & $\begin{array}{l}\text { Large amounts of data are } \\
\text { needed to get the probability } \\
\text { density functions, which } \\
\text { consume much more manpower } \\
\text { and material resources. }\end{array}$ \\
\hline $\begin{array}{l}\text { Interval nonprobabilistic } \\
\text { reliability }\end{array}$ & $\begin{array}{l}\text { The interval values of the } \\
\text { mechanical parameters. }\end{array}$ & $\begin{array}{l}\text { The interval values of the } \\
\text { parameters are easy to get } \\
\text { without the need of probability } \\
\text { density functions; the reliability } \\
\text { index can be obtained. }\end{array}$ & \\
\hline
\end{tabular}

By substituting the mean value and deviation of $c$ and $\varphi$ into (28) and using the method introduced in Section 3, the interval nonprobabilistic reliability index can be solved, and the interval nonprobabilistic reliability index $\beta$ was obtained.

$$
\begin{aligned}
Z= & M R-M S \\
= & 103.936 \times\left(0.0239+0.0127 \delta_{c}\right)+1.99601 \times 10^{6} \\
& \times\left(0.42325+0.40405 \delta_{f}\right)-789.469, \\
\beta= & 1.04654 .
\end{aligned}
$$

The random and fuzzy random reliability of the tailing dam were also calculated. The results show that the random and fuzzy random reliability are 0.9639 and 0.8555 , respectively, which means that the two kinds of reliability indexes are 1.8 and 1.06. The interval nonprobabilistic reliability index is less than those two reliability indexes but bigger than the threshold 1 . The results suggest that the tailing dam is in a reliable status. Actually, a serious earthquake with the magnitude of 6.1 occurred in the juncture of Panzhihua and Liangshan on August 30, 2008. The tailing dam is stable during the earthquake and no crack occurs. It also proved that the established interval nonprobabilistic reliability model is a reliable one. Although the three reliability indexes are all bigger than 1, note that the fuzzy random reliability index and the interval nonprobabilistic reliability index are too close to the threshold 1; the monitoring of the tailing dam should be taken seriously in case that disaster happens.

The safety factor can be applied when the data is sufficient using the mean values of the parameters. However, the uncertainty of the mechanical parameters is not considered. The random reliability is the preferred method when sufficient data are available to describe the uncertainty of the mechanical parameters; the random reliability is heavily dependent on the probability distributions, but a probability density function obtained according to insufficient data is inaccuracy; therefore, the results obtained may be unreliable. The interval nonprobabilistic reliability model is appropriate when there is not a sufficient amount of data to determine the probability density distribution and also the conditions that the data is sufficient. Furthermore, the uncertainty of the mechanical parameters is considered when determining the interval values. The advantages and disadvantages of the safety factor, the random reliability, and the nonprobabilistic reliability are listed in Table 5.

The established model of the interval nonprobabilistic reliability of the tailing dam provides a beneficial complement to the safety factor and the random reliability method and is not meant to replace them. The interval nonprobabilistic reliability model is appropriate when there is not a sufficient amount of data to determine the probability density distribution. Therefore, a strict data requirement is unnecessary because the uncertainty of the parameter value can be used when there is not a sufficient amount of data.

\section{Sensitive Analysis}

To compare and analyze the sensitivity of each interval parameter on the interval nonprobabilistic reliability, make the deviation of parameters $c_{1}$ and $f_{1}$ of the tailing dam change 0.002 toward both sides each time based on the previous deviation when calculating the interval nonprobabilistic reliability. The analysis process for the tailing dam of Hengyang can be classified into 2 conditions:

(1) $c_{1}^{c}, c_{1}^{r}$, and $f_{1}^{c}$ are set as constant values, and $f_{1}^{r}$ is set to $0.08075,0.08275,0.08475,0.08675,0.08875,0.09075$, $0.09275,0.09475,0.09675,0.09875$, and 0.10075 . These values are substituted into (20); the corresponding interval nonprobabilistic reliabilities are obtained according to (13) and 


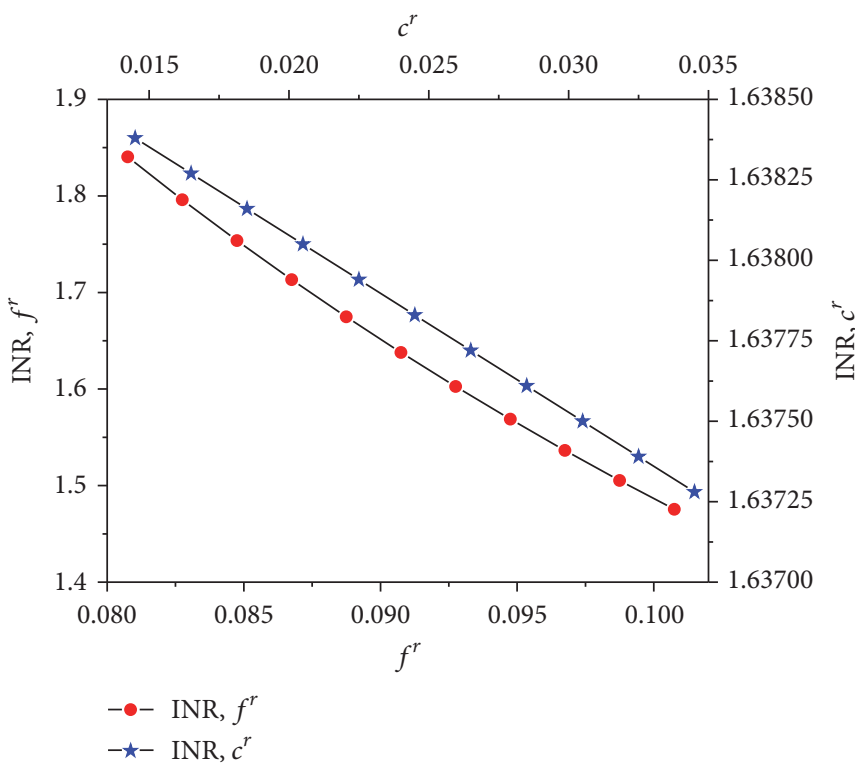

(a)

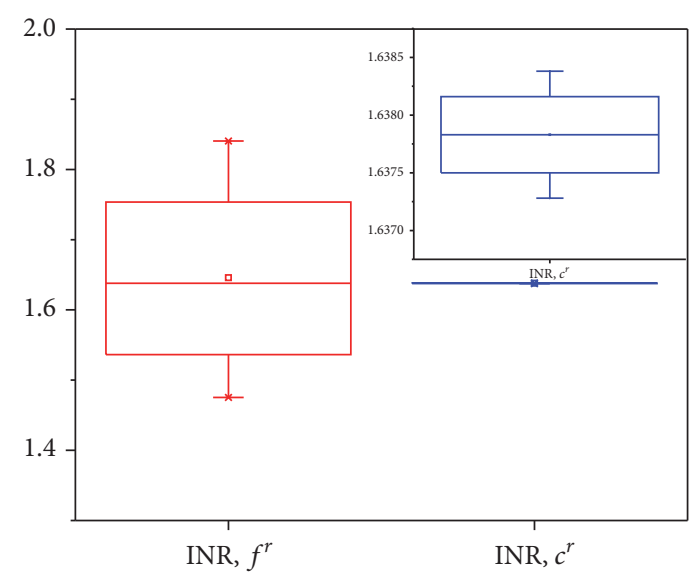

(b)

FIGURE 5: (a) Sensitivity analysis for the deviation of $c_{1}\left(c_{1}^{r}\right)$ and of $f_{1}\left(f_{1}^{r}\right)$ and (b) box charts for INRs under changes of $c_{1}\left(c_{1}^{r}\right)$ and $f_{1}\left(f_{1}^{r}\right)$.

(14). The change regulation is shown as solid blue star in Figure 5(a). A slight change in $f_{1}^{r}$ can change the stability of a tailing dam considerably.

(2) $c_{1}^{c}, f_{1}^{c}$, and $f_{1}^{r}$ are set as constant values, and $c_{1}^{r}$ is set to $0.0145,0.0165,0.0185,0.0205,0.0225,0.0245,0.0265,0.0285$, $0.0305,0.0325$, and 0.0345 . With the same solution as (1), the relationship between $c^{r}$ and the interval nonprobabilistic reliabilities of the tailing dam are obtained, as the solid red circle shown in Figure 5(a). From Figure 5(a), the relationship between $c^{r}$ and the interval nonprobabilistic reliabilities is found to be a nearly linear dependence, and the changes in $c_{1}^{r}$ have a minor effect on the interval nonprobabilistic reliabilities.

The relationship between shear strength ( $c$ and $f$ ) and the interval nonprobabilistic reliability can be obtained through the box chart in Figure 5(b). From Figure 5(b), it can be also clearly seen that the interval nonprobabilistic reliability is more sensitive to the change of $f$ than to the change of $c$.

To compare and analyze the sensitivity of each interval parameter on the interval nonprobabilistic reliability, make the deviation of parameters $f_{2}$ and $c_{12}$ of the tailing dam change 0.002 toward both sides each time based on the previous deviation when calculating the interval nonprobabilistic reliability. The analysis process for the tailing dam of Panzhihua can be classified into 2 conditions:

(1) $c_{2}^{c}, c_{2}^{r}$, and $f_{2}^{c}$ are set as constant values, and $f_{2}^{r}$ is set to $0.39405,0.39605,0.39805,0.40005,0.40205,0.40405$, $0.40605,0.40805,0.41005,0.41205$, and 0.41405 . These values are substituted into (28); the corresponding interval nonprobabilistic reliabilities are obtained according to (13) and (14). The change regulation is shown as solid blue star in Figure 6(a). A slight change in $f_{2}^{r}$ can change the stability of a tailing dam considerably.
(2) $c_{2}^{c}, f_{2}^{c}$, and $f_{2}^{r}$ are set as constant values, and $c_{2}^{r}$ is set to $0.0027,0.0047,0.0067,0.0087,0.0107,0.0127,0.0147,0.0167$, $0.0187,0.0207$, and 0.0227 . With the same solution as (1), the relationship between $c_{2}^{r}$ and the interval nonprobabilistic reliabilities of the tailing dam is obtained, as the solid red circle shown in Figure 6(a). From Figure 6(a), the relationship between $c_{2}^{r}$ and the interval nonprobabilistic reliabilities is found to be a horizontal dependence. By analyzing the values of the parameter $c_{2}$ we can find that the values of $c_{2}$ are much less than that of $c_{1}$, which resulted in a very small deviation. From Figure 6(a) we can discover that the changes in $c_{2}^{r}$ have a minor effect on the interval nonprobabilistic reliabilities.

The relationship between shear strength ( $c$ and $f$ ) and the interval nonprobabilistic reliability can be obtained through the box chart in Figure 6(b). From Figure 6(b), it can be also clearly seen that the interval nonprobabilistic reliability is more sensitive to the change of $f$ than to the change of $c$.

\section{Conclusions}

The phreatic line significantly affects the stability of the tailing dam; a new interval nonprobabilistic reliability measurement and analysis method for tailing dam with the consideration of the existence of phreatic line was proposed based on the interval theory. This proposed method requires the values of the bounds of the uncertain parameters but not their specific distributions. As a result, the initial data requirements are reduced considerably.

The developed interval nonprobabilistic reliability method was used to evaluate the stability of two tailing dams in China. The calculation results of the interval nonprobabilistic reliability are found to be in agreement with actual situations. It is concluded that the interval nonprobabilistic 


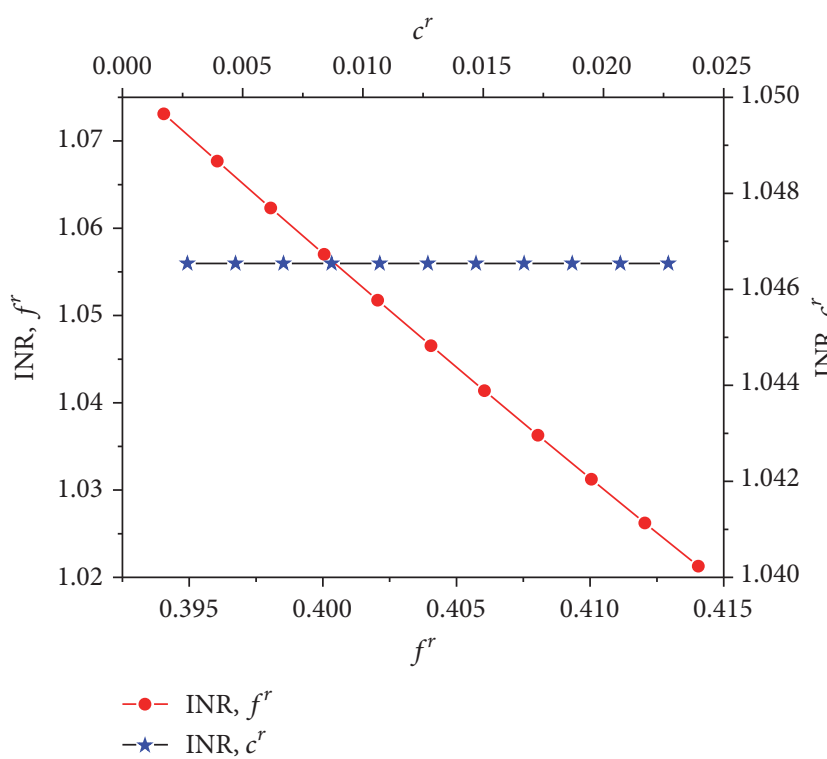

(a)

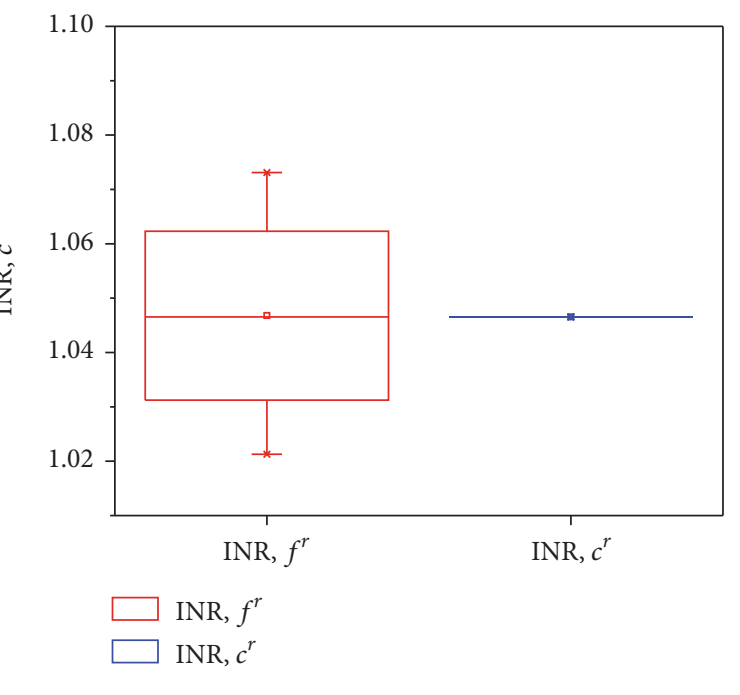

(b)

FIGURE 6: (a) Sensitivity analysis deviation of $c_{2}\left(c_{2}^{r}\right)$ and $f_{2}\left(f_{2}^{r}\right)$ and (b) box charts for INRs under changes of $c_{2}\left(c_{2}^{r}\right)$ and $f_{2}\left(f_{2}^{r}\right)$.

reliability method can be used when the amount of data is scarce.

The most sensitive mechanical parameters of the tailing dam failure can be determined through a sensitivity analysis of the mechanical parameters toward the interval nonprobabilistic reliability, thereby providing instructions for the support of the tailing dam slope.

It is noted that the nonprobabilistic reliability method is not designed to replace the probabilistic reliability method but instead serves as a useful complement to the probabilistic reliability method. The probability reliability method can be used when there is a sufficient amount of data to describe the probability properties of the uncertain parameters, and the interval nonprobabilistic reliability models can be used when the uncertainty in the data is scare.

\section{Conflicts of Interest}

The authors declare that there are no conflicts of interest regarding the publication of this paper.

\section{Acknowledgments}

The authors wish to acknowledge financial support from the China Postdoctoral Science Foundation (2015M570688, 2016T90639), the Young Elite Scientists Sponsorship Program by CAST (YESS20160175), and Innovation-Driven Project of Central South University (2016CXS001).

\section{References}

[1] S.-H. Jiang, J. Huang, and C.-B. Zhou, "Efficient system reliability analysis of rock slopes based on Subset simulation," Computers and Geotechnics, vol. 82, pp. 31-42, 2017.
[2] S.-H. Jiang and J.-S. Huang, "Efficient slope reliability analysis at low-probability levels in spatially variable soils," Computers and Geotechnics, vol. 75, pp. 18-27, 2016.

[3] F.-Y. Wang, Z.-S. Xu, and L.-J. Dong, "Stability model of tailing dams based on fuzzy random reliability," Chinese Journal of Geotechnical Engineering, vol. 30, no. 11, pp. 1600-1605, 2008.

[4] L. Dong and X. Li, "Comprehensive models for evaluating rockmass stability based on statistical comparisons of multiple classifiers," Mathematical Problems in Engineering, vol. 2013, Article ID 395096, 9 pages, 2013.

[5] L.-J. Dong, J. Wesseloo, Y. Potvin, and X.-B. Li, "Discriminant models of blasts and seismic events in mine seismology," International Journal of Rock Mechanics \& Mining Sciences, vol. 86, pp. 282-291, 2016.

[6] W.-X. Li, D.-L. Qi, S.-F. Zheng, J.-C. Ren, J.-f. Li, and X. Yin, "Fuzzy mathematics model and its numerical method of stability analysis on rock slope of opencast metal mine," Applied Mathematical Modelling, vol. 39, no. 7, pp. 1784-1793, 2015.

[7] M. Xiang, Y. Xu, C.-Y. Li, Y. Liu, and Y. Zhang, "Energy conservation co-operative control mechanism based on gray prediction for structural air compressor," Automation in Construction, vol. 30, no. 30, pp. 184-190, 2013.

[8] Y.-H. Lin, J.-S. Wang, and P.-F. Pai, "A grey prediction model with factor analysis technique," Journal of the Chinese Institute of Industrial Engineers, vol. 21, no. 6, pp. 535-542, 2004.

[9] F.-M. Tseng, H.-C. Yu, and G.-H. Tzeng, "Applied hybrid grey model to forecast seasonal time series," Technological Forecasting and Social Change, vol. 67, no. 2-3, pp. 291-302, 2001.

[10] C.-H. Wang, "Predicting tourism demand using fuzzy time series and hybrid grey theory," Tourism Management, vol. 25, no. 3, pp. 367-374, 2004.

[11] L. J. Dong, J. Wesseloo, Y. Potvin, and X. B. Li, "Discrimination of mine seismic events and blasts using the fisher classifier, naive bayesian classifier and logistic regression," Rock Mechanics and Rock Engineering, vol. 49, no. 1, pp. 183-211, 2016. 
[12] S. H. Ni, P. C. Lu, and C. H. Juang, "A fuzzy neural network approach to evaluation of slope failure potential," ComputerAided Civil and Infrastructure Engineering, vol. 11, no. 1, pp. 5966, 1996.

[13] F. Mayoraz and L. Vulliet, "Neural networks for slope movement prediction," International Journal of Geomechanics, vol. 2, no. 2, pp. 153-173, 2002.

[14] W. D. Jiang and X. B. Li, "Spatiotemporal chaos model of seepage linein tailings dam and its back analysis," Journal of Central South University of Technology, vol. 34, no. 6, pp. 704707, 2003.

[15] K. Hornik, M. Stinchcombe, and H. White, "Universal approximation of an unknown mapping and its derivatives using multilayer feedforward networks," Neural Networks, vol. 3, no. 5, pp. 551-560, 1990.

[16] L. Dong, X. Li, and G. Xie, "Nonlinear methodologies for identifying seismic event and nuclear explosion using random forest, support vector machine, and naive Bayes classification," Abstract and Applied Analysis, vol. 2014, Article ID 459137, 8 pages, 2014.

[17] M.-J. Hu, A.-G. Guo, and S.-Y. Chen, "Reflections on anti-slide stability analysis of a gangue dam," Rock and Soil Mechanics, vol. 25, no. 5, pp. 769-773, 2004.

[18] G. E. Blight, "Destructive mudflows as a consequence of tailings dyke failures," Proceedings of the Institution of Civil Engneers Geotechnical Engineering, vol. 125, no. 1, pp. 9-18, 1997.

[19] S. Moxon, "Failing again," International Water Power and Dam Construction, vol. 51, no. 5, pp. 16-21, 1999.

[20] M. Rico, G. Benito, and A. Díez-Herrero, "Floods from tailings dam failures," Journal of Hazardous Materials, vol. 154, no. 1-3, pp. 79-87, 2008.

[21] J. Li, C. P. Li, C. M. Li et al., "Forecasting of infiltration route in tailing dam by support vector regression," Journal of Safety Science \& Technology, vol. 5, no. 1, pp. 76-79, 2009.

[22] F. Y. Wang, Research on stability analysis and comprehensive assessment of the Tailing dam based on the uncertainty theory [Ph.D. thesis], Central South University, Changsha, 2009.

[23] Q. Jiang and Y. Tang, "A general approximate method for the groundwater response problem caused by water level variation," Journal of Hydrology, vol. 529, no. 1, pp. 398-409, 2015.

[24] Y. Tang, Q. Jiang, and C. Zhou, "Approximate analytical solution to the Boussinesq equation with a sloping water-land boundary," Water Resources Research, vol. 52, no. 4, pp. 2529-2550, 2016.

[25] J. M. Duncan, "Factors of safety and reliability in geotechnical engineering," Journal of Geotechnical and Geoenvironmental Engineering, vol. 126, no. 4, pp. 307-316, 2000.

[26] G. Wang and Z. Ma, "Hybrid particle swarm optimization for first-order reliability method," Computers and Geotechnics, vol. 81, pp. 49-58, 2017.

[27] S.-X. Guo and Z.-Z. Lu, "A non-probabilistic robust reliability method for analysis and design optimization of structures with uncertain-but-bounded parameters," Applied Mathematical Modelling, vol. 39, no. 7, pp. 1985-2002, 2015.

[28] B. Y. Ni, C. Jiang, and X. Han, "An improved multidimensional parallelepiped non-probabilistic model for structural uncertainty analysis," Applied Mathematical Modelling, vol. 40, no. 78, pp. 4727-4745, 2016.

[29] M. S. Chowdhury, C. Song, W. Gao, and C. Wang, "Reliability analysis of homogeneous and bimaterial cracked structures by the scaled boundary finite element method and a hybrid random-interval model," Structural Safety, vol. 59, pp. 53-66, 2016.

[30] Y. Ben-Haim, S. Cogan, and L. Sanseigne, "Usability of mathematical models in mechanical decision processes," Mechanical Systems and Signal Processing, vol. 12, no. 1, pp. 121-134, 1998.

[31] T. Jiang, J. Chen, P. Jiang et al., "A one-dimensional optimization algorithm for non-probabilistic reliability index," Engineering Mechanics, vol. 24, no. 7, pp. 23-27, 2007.

[32] S. X. Guo, Z. Z. Lv, and Y. S. Feng, "A non-probabilistic model of structural reliability based on interval analysis," Chinese Journal of Computational Mechanics, vol. 18, no. 1, pp. 56-60, 2001.

[33] L.-J. Dong and X.-B. Li, "Study of interval parameters and credibility of representative value of rock tensile and compression strength tests," Chinese Journal of Geotechnical Engineering, vol. 32, no. 12, pp. 1969-1974, 2010. 

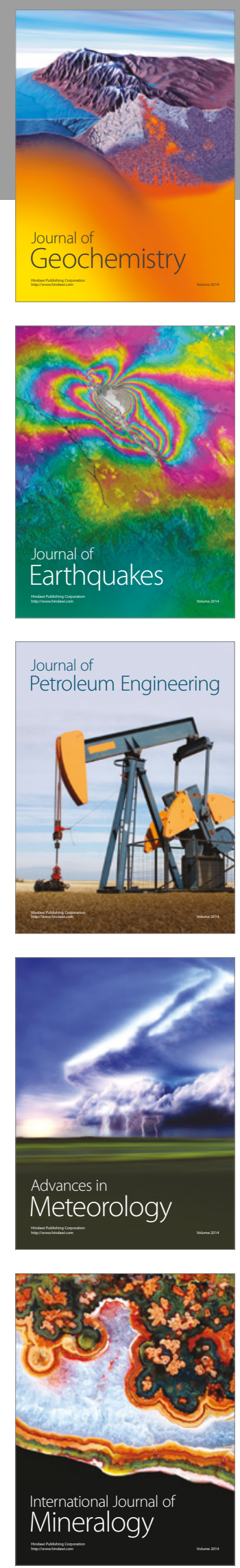
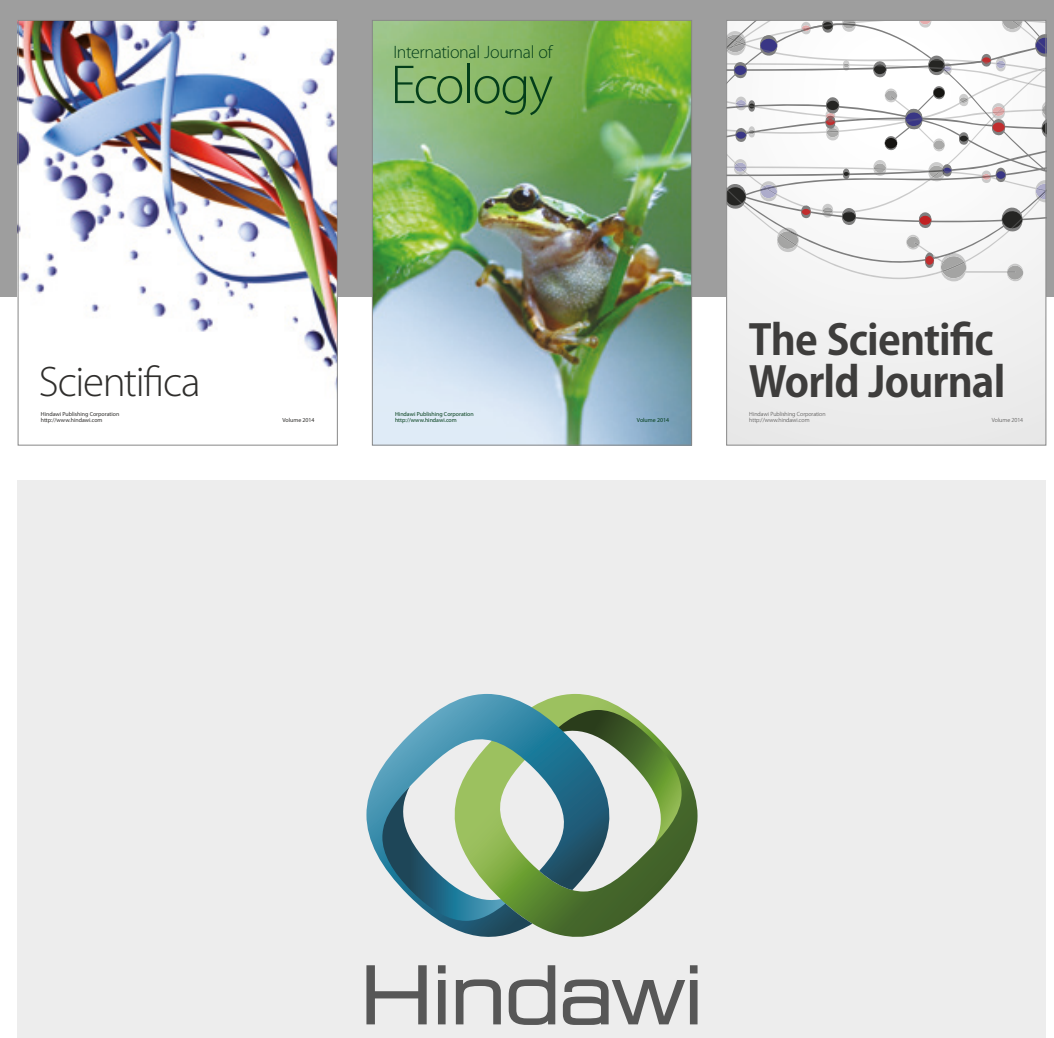

Submit your manuscripts at

https://www.hindawi.com
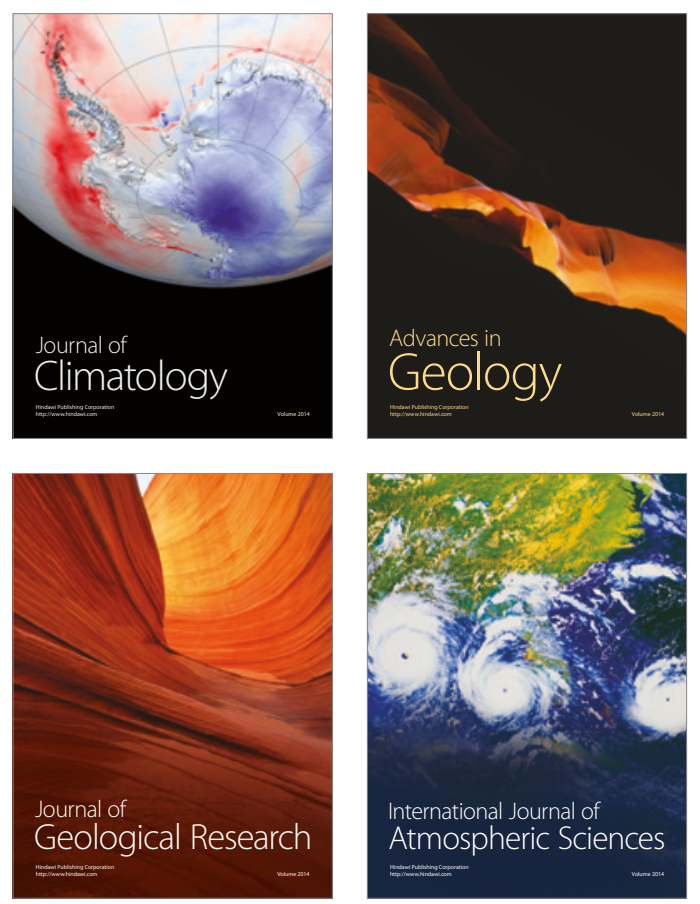

The Scientific

World Journal
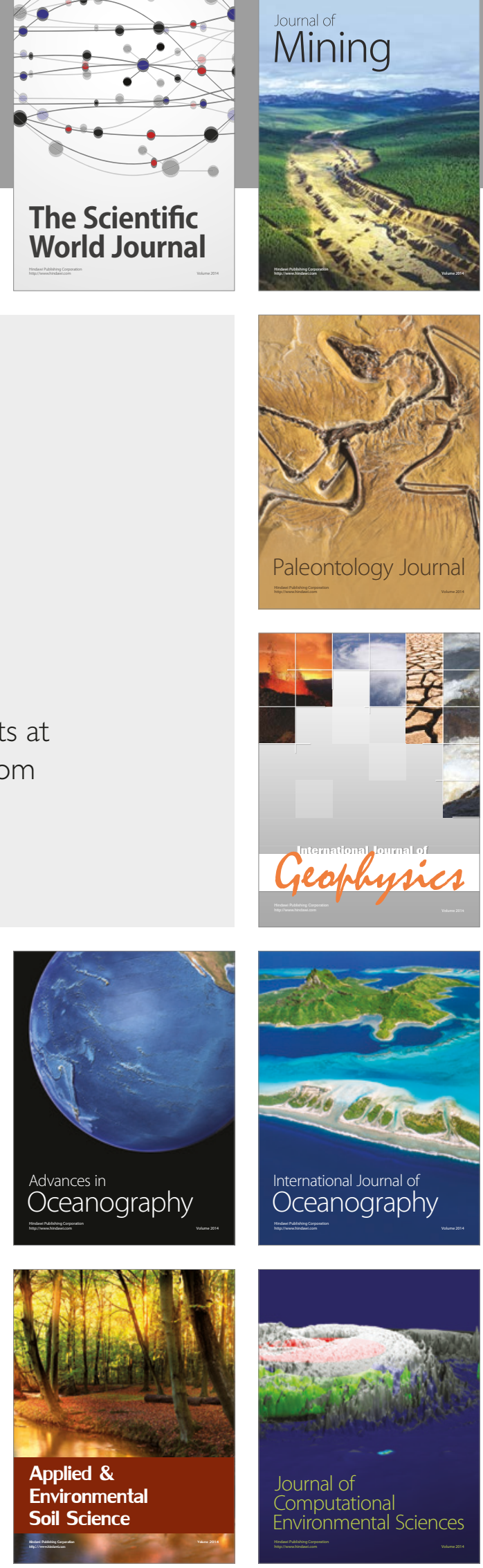